\title{
Forecasting an eruption
}

\author{
Florent Brenguier, Valérie Ferrazzini and their colleagues braved tropical cyclones and crater \\ collapses while recording continuous seismological data on the Piton de la Fournaise volcano.
}

\begin{abstract}
How was this work initiated? What was the objective of the work at the beginning of the project? A couple of years back, Michel Campillo and Nikolai Shapiro presented a new method for processing ambient seismic noise in order to characterize geological structures. As we already had continuous seismological data for the Piton de la Fournaise volcano since 1999, we thought we would try to use this method not only to extract information regarding the structure of this volcano but also to understand its evolution through time. We therefore initiated collaborative work with the staff of the Piton de la Fournaise Volcanological Observatory, directed by Thomas Staudacher.
\end{abstract}

Why did you choose this particular location for the fieldwork (or did you find it by chance)?

Piton de la Fournaise is one of the most active volcanoes in the world. Since 1998, it has erupted 27 times, with eruptions lasting anywhere from a few hours to six months. This volcano benefits from a dense network of seismometers and is thus an ideal site to develop and test new methods to forecast eruptions that can be applied to other more dangerous volcanoes where timely forecasts are critical.

\section{What sorts of data or samples were you after?}

We wanted to digitally record seismic waves. Such waves can periodically be generated by earthquakes or nuclear explosions, but we were interested in recording the very small yet continuous motions of the ground that are generated by the interaction of ocean waves with

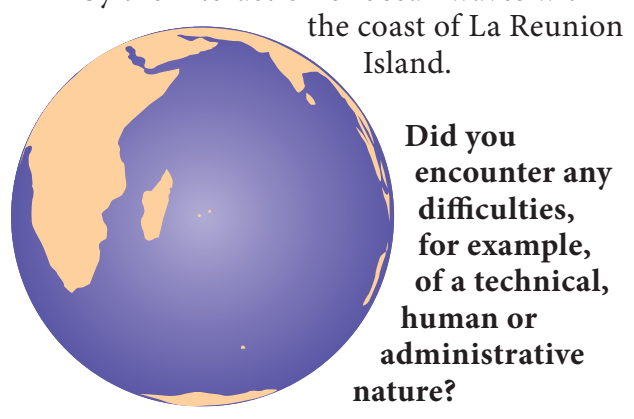

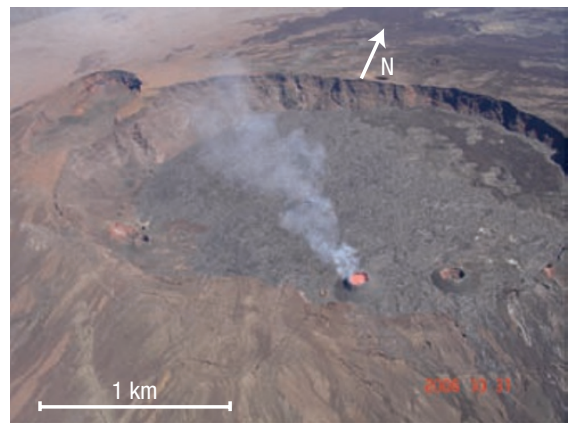

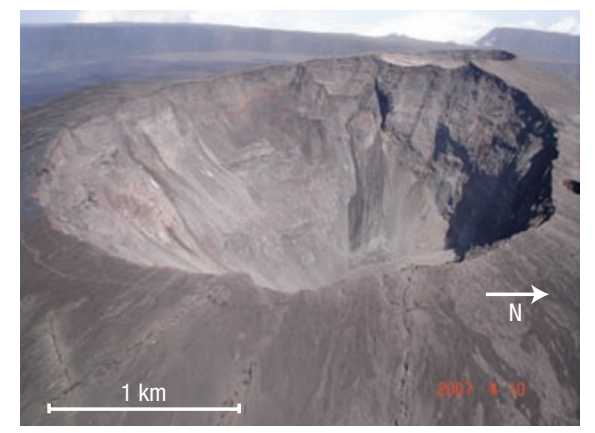

Photographs showing Dolomieu crater before (left) and after (right) its collapse. The depth of the crater after collapse was $300 \mathrm{~m}$. Images courtesy of Thomas Staudacher, Piton de la Fournaise Volcanological Observatory.

What caused us most difficulties was not volcanic activity but the strong tropical cyclones that occur in the austral summer, between November and March. On some days we faced winds with velocities as high as $200 \mathrm{~km}$ per hour that dumped up to a few metres of rainfall on the volcanic edifice. The consequences were bent antennas and twisted solar panels that had to be replaced immediately. But the worst damage was caused by lightning bolts that dominantly occur in the nearby high cliffs surrounding the main caldera and that literally burned every little piece of instrument. Installing the instruments that transferred data to the observatory in real time by radio was also not easy. The observatory is situated about $15 \mathrm{~km}$ west of the central part of the volcano and it takes hours of walking from the road to reach most of the seismic stations.

\section{Any memorable experiences?}

In the beginning of April 2007, a huge eruption occurred and led to the collapse of the Dolomieu crater. The surroundings were strictly forbidden to the public but in order to avoid failure of power to the seismological and deformation stations located near the collapsed crater, it was absolutely necessary for us to rid the solar panels of the volcanic ash covering them. We therefore decided to do that on 8 April - that also gave us a chance to collect the volcanic ash for geochemical analysis. We took all the necessary precautions, but it sent a chill up our spines when, four days later, part of the structure supporting the seismological station collapsed into the 300-metredeep crater! What is more, on 25 May, a deformation station and our summit web camera met the same fate.

Was the data analysis straightforward or were there any problems associated with it?

The analysis was certainly not easy and was in fact rather tedious. It took one whole compact disk to record one day's worth of signals. Hence we had to analyse data on 540 disks with a single computer!

Did the trip give you any ideas for future research projects? Most definitely! We now intend to use this newly developed technique for real-time monitoring of the volcano's activity. This should improve our ability to forecast eruptions and to assess their intensity and environmental impact well in advance.

This is the Backstory to work by Florent Brenguier, Valérie Ferrazzini, and their colleagues, published on page 126 of this issue. 